\title{
Conflicting Duties and Reciprocal Obligations During a Pandemic
}

\author{
Armand H. Matheny Antommaria, MD, $\mathrm{PhD}^{1,2}$
}

${ }^{1}$ Ethics Center and the Division of Hospital Medicine, Cincinnati Children's Hospital Medical Center, Cincinnati, Ohio; ${ }^{2}$ Department of Pediatrics, University of Cincinnati School of Medicine, Cincinnati, Ohio.

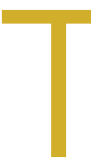
he current COVID-19 pandemic has raised substantial anxieties and fears for healthcare workers, many of which they have not previously encountered. Important ethical issues have arisen involving the tension between their duties to their patients and their duties to themselves and to their loved ones. While these fears and duties are not unique to physicians or to members of one specialty, this article will focus on hospitalists. In general, hospitalists have an obligation to care for patients even if this puts them at risk, but duties to patients may at times be constrained by duties to others. At the same time, hospitals have correlative obligations to protect their employees and mitigate risk. Balancing these duties requires weighing benefits and risks, often in the context of considerable uncertainty. At this current time, it is conceivable that the risks may become so great that caring for patients is no longer obligatory but becomes heroic.

Conflicting duties arise in a variety of ways. Hospitalists are at increased risk of contracting the virus, given workplace exposures. The risk of complications is even higher for those who are older or have chronic medical conditions. Further, the shortage of personal protective equipment (PPE) adds to the overall risk. Hospitalists may also have concerns about transmitting the virus to family members or friends, especially to those who are elderly or have comorbidities. Hospitalists may also become physically and emotionally exhausted as work and home demands increase. Concerns for the care of dependents adds to the stress as daycares and schools close and older relatives are isolated in their homes. Hospitalists who are single parents and those whose partners are also healthcare workers are especially affected. The duty to care, encumbered by the cumulative stressors, creates an environment ripe for conflict.

\section{DUTY TO CARE}

Hospitalists have a duty to expose themselves to some, albeit not unlimited, risks. There are different ways of characterizing this obligation. ${ }^{1}$ Some base it in the knowledge and power differential between physicians and patients, a differential increased by patients' illnesses. Others frame it as a social contract: physicians receive certain benefits and privileges and, in accepting them, incur certain duties. Physicians practicing

Corresponding Author: Armand H. Matheny Antommaria, MD, PhD; Email: armand.antommaria@cchmc.org.

Published online first April 3, 2020

Received: March 30, 2020; Revised: April 1, 2020; Accepted: April 1, 2020

C 2020 Society of Hospital Medicine DOI 10.12788/jhm.3425 in the 1980s may recall a similar discussion about treating patients with the human immunodeficiency virus (HIV), while those who practiced in other countries in the early 2000s faced a similar conflict during the severe acute respiratory syndrome (SARS) epidemic, caused by another coronavirus. ${ }^{2}$ The expectation of accepting risk may have been weakened in the last several decades, however, by the relative lack of risk in treating hospitalized patients in the United States.

\section{DUTIES TO SELF AND OTHERS}

Hospitalists' duties to themselves and to their families are both intrinsically and instrumentally important. Being a hospitalist is not every hospitalist's sole or predominant identity. They may also be adult children, spouses, and/or parents, or school board members or leaders in religious communities. Each of these roles entails its own duties and fulfilling them is also important. Effectuating them may, however, be more difficult because of the pandemic. Adult children may feel obligated to shop for their parents and parents of young children may have more childcare obligations. If no one else can fulfill these duties, they might take precedence over professional duties.

By fulfilling their duties to themselves and others, hospitalists may also be enabled to serve their patients. Unlike some discrete events, such as mass shootings or tornados, for which contingency and crisis standards of care may last for hours or days, we may be working under altered standards of care for weeks or months. (A contingency standard of care involves doing things differently in order to produce comparable clinical outcomes. A crisis standard of care is reached when it's no longer possible to produce comparable clinical outcomes and the focus shifts from individual patient's best interests or preferences to trying to save the most lives. ${ }^{3}$ ) It, therefore, is important we maintain our health and well-being by getting adequate sleep, eating well, and exercising. ${ }^{4}$ Arranging alternative childand eldercare may reduce distractions at work and decrease the chance of needing to leave work unexpectedly.

\section{MINIMIZING RISKS}

In addressing these ethical issues, one of the key considerations is reducing the risks. We can reduce some risks ourselves while maintaining comparable outcomes to our conventional practices. I hope that it would go without saying, for example, that we should not work when we are sick. It is also important that we engage in adequate physical distancing whenever possible. It is important that physical distancing measures be applied equitably to all employees and that the actions hospitalists take to reduce their exposure do not dis- 
proportionately burden trainees or other types of providers. Consider, for example, having residents or nurse practitioners examine patients instead of the attending physician. This places subordinates at greater risk. Attending physicians, however, may have the best examination skills and their feedback is integral to trainees' learning. Modeling a commitment to the duty to care and equitably accepting risk is exceptionally important as team members and leaders.

We can check in with one another and support each other emotionally. If some colleagues have substantially higher risks of complications, they may be assigned alternative duties with lower exposure risks. As a relatively young specialty, this may be more feasible for hospitalists than other specialties with a greater number of older practitioners. Care, however, should be taken to respect individuals' privacy and confidentiality.

\section{RECIPROCAL OBLIGATIONS}

Minimizing risk is also a responsibility of hospitals and the local, state, and federal government. They have crucial roles in, for example, establishing adequate infection control policies and securing sufficient PPE. Many institutions have already moved to contingency standards of care to conserve PPE. ${ }^{5}$ These efforts not only support the duty of reciprocity ${ }^{6}$ but also help maintain an adequate workforce by reducing sick leave. The government's apparent failure to fulfill its obligation to stockpile and distribute adequate equipment is currently being acutely felt. ${ }^{7}$

There are other potential actions that facilities can take, such as providing scrubs, child- and eldercare, housing, or life insurance. Individuals may be concerned about infecting family members. There is unfortunately limited data about spread on objects or asymptomatic spread, but these are reasonable possibilities. Facilities can provide scrubs to employees who do not normally wear them to provide a further barrier between the facility and the employees' homes. They can provide child and elder care. It has been wonderful to see local community organizations and groups of medical students provide childcare for healthcare workers and other essential employees. $^{8}$ Healthcare facilities could also consider providing temporary housing to staff with family members at high risk of complications. During the Ebola outbreak, some facilities provided supplemental disability and life insurance to staff who volunteered to put themselves at risk to help assure that their families would be provided for if the staff member unfortunately contracted the virus and became disabled or died.

Reciprocal duties to healthcare workers in a crisis standard of care are unresolved. Establishing ethically and clinically sound ventilator triage criteria is complex. 9,10 Some argue that healthcare providers should have some degree of priority. One argument is that if they recover, they can return to work and save more lives. (Having individuals who have recovered and are theoretically immune treat patients without PPE is one proposed conservation strategy.) It is, however, unclear whether individuals are likely to recover in enough time to return to work while we are still in a crisis standard of care. A different argument is that healthcare workers should be given priority because they accepted risk. This assumes they were infected at work and not in the community. While this argument has merit, it could be influenced by or perceived to be influenced by self-interest. Prioritizing healthcare workers for scarce resources requires substantial community support. ${ }^{11}$

\section{LIMITATIONS}

While providers have a duty to accept some risks, this duty is not unlimited. The mitigation strategies may be unsuccessful, and the risks substantial. One can think of analogies in other fields. Firefighters, for example, expose themselves to risk to save lives and to protect property. They are trained to take calculated risks, considering the likelihood and type of benefit and the degree of risk, but not to be reckless. They will take greater risk to save a life than property, and less risk if the victim is unlikely to survive. Their obligation to accept risk is not unlimited. They may justifiably choose not to enter a building, which is at significant, imminent risk of collapse, to protect property. The same is true for physicians. They are obligated to expose themselves to some risk, but not at a high likelihood of serious injury or death. At some point the duty to care for patients becomes supererogatory; fulfilling the duty is no longer required but becomes optional and doing so is heroic. ${ }^{12}$ Some facilities, for example, will not perform cardiopulmonary resuscitation under a crisis standard of care due to the high risk of exposure and the low likelihood of success. ${ }^{13}$

\section{DECISION-MAKING PROCESS}

Weighing potential benefits and risk is difficult. This difficulty is exacerbated by uncertainty. Some decisions would be easier, for example, if there was better evidence regarding asymptomatic spread. Finally, the subjectivity of some of these decisions raises concerns about unconscious bias or self-interest. It is therefore valuable to make some decisions collectively rather than individually. In particular, it is important to include those with adequate situation awareness. Conversely, once decisions are made, it is valuable to communicate both the decision and its rationale, and to be open to revising them based on feedback.

Given the fear and uncertainty generated by the pandemic, some individuals may be tempted to act unethically. Individuals have, unfortunately, taken hospital supplies, such as masks and hand sanitizer, for household use, and healthcare providers have hoarded medications, such as hydroxychloroquine. ${ }^{14}$ Individuals may also be tempted to use PPE for encounters when it is not indicated. We should address these fears and anxieties in other ways, such as discussing them with colleagues, chaplains, social workers, or employee assistance programs. If you observe coworkers acting in a manner that appears to be unethical, it is important to address their behavior while still giving them the benefit of the doubt. If you do not receive a satisfactory response, you should utilize the appropriate chain of command.

\section{CONCLUSIONS}

Most hospitalists are encountering situations that they have not previously experienced in their careers. These situations 
generate significant fear and anxiety. Many of these situations involve tensions between our duties to our patients and our duties to ourselves and to our families and friends. This tension is heightened for individuals who are older or have chronic health conditions or have family members who are. While healthcare providers have an obligation to accept some risks, this duty is not unlimited. Hospitals, healthcare systems, and governments have reciprocal obligations to keep providers safe. It is important to think creatively about ways to minimize risk. Due to uncertainty and self-interest, it may be better to make decisions collectively and transparently.

Disclosures: Dr Antommaria has no conflicts of interest to disclose.

\section{References}

1. Malm H, May T, Francis LP, Omer SB, Salmon DA, Hood R. Ethics, pandemics, and the duty to treat. Am J Bioeth. 2008;8(8):4-19. https:// doi:10.1080/15265160802317974

2. Dwyer J, Tsai DF. Developing the duty to treat: HIV, SARS, and the next epidemic. J Med Ethics. 2008;34(1):7-10. https://doi: 10.1136/jme.2006.018978.

3. Hick JL, Barbera JA, Kelen GD. Refining surge capacity: conventional, contingency, and crisis capacity. Disaster Med Public Health Prep. 2009;3(2 Suppl):S59-S67. https://doi:10.1097/DMP.0b013e31819f1ae2.

4. Centers for Disease Control and Prevention. Emergency Responders: Tips for Taking Care of Yourself. March 19, 2018. https://emergency.cdc.gov/coping/responders.asp. Accessed March 30, 2020.

5. Centers for Disease Control and Prevention. Coronavirus Disease 2109 (COVID-19): Facemasks. March 17, 2020. https://www.cdc.gov/coronavirus/2019-ncov/hcp/ppe-strategy/face-masks.html. Accessed March 30, 2020.
6. Pandemic Influenza Working Group. Stand on Guard for Thee: Ethical Considerations in Preparedness Planning for Pandemic Influenza. Toronto: University of Toronto Joint Centre for Bioethics; 2005. http://www.jcb.utoronto. ca/people/documents/upshur_stand_guard.pdf. Accessed March 30, 2020.

7. Miroff N. Protective gear in national stockpile is nearly depleted, DHS officials say. The Washington Post. April 1, 2020. https://www.washingtonpost. $\mathrm{com} /$ national/coronavirus-protective-gear-stockpile-depleted/2020/04/01/ 44d6592a-741f-11ea-ae50-7148009252e3_story.html. Accessed April 2, 2020.

8. Lewis T. Medical students provide childcare for healthcare professionals during COVID-19 pandemic. Fox 5 DC. March 27, 2020. https://www.fox5dc. $\mathrm{com} / \mathrm{news} / \mathrm{medical}$-students-provide-childcare-for-healthcare-professionals-during-covid-19-pandemic. Accessed March 30, 2020.

9. New York State Task Force on Life and the Law. Ventilator Allocation Guidelines. New York: New York State Department of Health; 2015. https://www. health.ny.gov/regulations/task_force/reports_publications/docs/ventilator_ guidelines.pdf. Accessed March 30, 2020.

10. Antommaria AH, Powell T, Miller JE, Christian MD, Task Force for Pediatric Emergency Mass Critical Care. Ethical issues in pediatric emergency mass critical care. Pediatr Crit Care Med. 2011;12(6 Suppl):S163-168. https:// doi:10.1097/PCC.0b013e318234a88b.

11. Rothstein, MA. Currents in contemporary ethics. Should health care providers get treatment priority in an influenza pandemic? J Law Med Ethics. 2010; 38(2):412-419. https://doi:10.1111/j.1748-720X.2010.00499.x.

12. Ruderman C, Tracy CS, Bensimon CM, et al. On pandemics and the duty to care: whose duty? who cares? BMC Med Ethics. 2006;7:E5. https://doi. org/10.1186/1472-6939-7-5.

13. Cha AE. Hospitals consider universal do-not-resuscitate orders for coronavirus patient. The Washington Post. March 25, 2020. https://www.washingtonpost.com/health/2020/03/25/coronavirus-patients-do-not-resucitate/. Accessed March 30, 2020

14. Sanders T, Armstrong D, Kofman A. Doctors are hoarding unproven coronavirus medicine by writing prescriptions for themselves and their families. ProPublica. March 24, 2020. https://www.propublica.org/article/ doctors-are-hoarding-unproven-coronavirus-medicine-by-writing-prescriptions-for-themselves-and-their-families. Accessed March 30, 2020. 